\title{
Genetic Factors in Lipoprotein Metabolism \\ Analysis of a Genetic Cross between Inbred Mouse Strains NZB/BINJ and SM/J Using a Complete Linkage Map Approach
}

\author{
Deborah A. Purcell-Huynh, ${ }^{*}$ Ari Weinreb, ${ }^{*}$ Lawrence W. Castellani, ${ }^{\star}$ Margarete Mehrabian, ${ }^{*}$ Mark H. Doolittle, ${ }^{\ddagger}$ \\ and Aldons J. Lusis* \\ *Department of Microbiology and Molecular Genetics, Department of Medicine, and Molecular Biology Institute, University of \\ California, Los Angeles, California 90024; and ${ }^{\ddagger}$ Wadsworth Veterans Administration Medical Center, Los Angeles, California 90073
}

\begin{abstract}
A genetic cross was constructed from two parental inbred strains of mice, NZB/B1NJ and SM/J, which differ markedly in their plasima lipoprotein levels. Plasma lipid and apolipoprotein values were measured in $184 \mathrm{~F} 2$ progeny on a normal chow diet and on an atherogenic diet. Genetic markers were typed àt 126 loci spanning all chromosomes except the Y. Statistical analysis revealed significant linkage or suggestive linkage of lipoprotein levels with markers on a number of chromosomes. Chromosome 1 markers were linked to levels of total cholesterol (lod 5.9) and high density lipoprotein (HDL) cholesterol (lod 8.1), chromosome 5 markers were linked to levels of total cholesterol (lod 6.7) and HDL cholesterol (lod 5.6), and chromosome 7 markers were linked to levels of total plasma triglycerides (lod 5.1) and free fatty acids (lod 5.6). Plasma apoAII levels were linked to the apoAII gene (lod score 19.6) and were highly correlated with plasma HDL cholesterol levels $(r=0.63, P$ $=0.0001$ ), indicating that apoAII expression influences HDL cholesterol levels. Molecular studies suggested that structural differences in the apoAII polypeptide of the two strains may contribute to differences in clearance of the protein. (J. Clin. Invest. 1995. 96:1845-1858.) Key words: apolipoprotein AII • atherosclerosis • genetic markers • high density lipoprotein $\bullet$ quantitative trait locus mapping
\end{abstract}

\section{Introduction}

The compositions and plasma levels of lipoproteins are strongly associated with atherosclerosis, a primary cause of heart disease and stroke. Thus, high levels of atherogenic lipoproteins, including low density and very low density lipoproteins (LDL and VLDL, respectively), are a prerequisite for most forms of cardiovascular disease. High density lipoprotein (HDL) levels, on the other hand, are inversely correlated with cardiovascular disease. Two approaches have proven useful in identifying the underlying genetic factors and biochemical pathways contributing to variations in atherosclerosis-related phenotypes. The first is the analysis of relatively rare Mendelian syndromes, such as familial hypercholesterolemia (1), familial hypobetalipopro-

Address correspondence to Aldons J. Lusis, Department of Medicine, Division of Cardiology, University of California, Los Angeles, Los Angeles, CA 90024. Phone: 310-825-1359; FAX: 310-794-7345.

Received for publication 22 December 1994 and accepted in revised form 30 May 1995.

The Journal of Clinical Investigation, Inc.

Volume 96, October 1995, 1845-1858 teinemia (2), lipoprotein lipase deficiency (3), cholesterol ester transfer protein deficiency $(4)$, and others $(5,6)$. However, such monogenic syndromes account for only a small fraction of the variance in plasma lipoproteins seen in the population. A second approach is to examine polymorphisms associated with "candidate genes" which are defined by biochemical studies of lipoprotein transport, either in whole populations (association studies) or families (linkage studies) (7). This approach has provided evidence that relatively subtle genetic variations in the genes for several apolipoproteins, lipases, lipid transfer proteins, and lipoprotein receptors contribute additively or cumulatively to lipoprotein metabolism. For example, the three major alleles of apolipoprotein $\mathrm{E}(\mathrm{apoE})$ which occur in the population have a significant influence over plasma cholesterol levels $(8,9)$. Both of the approaches described above are limited by their dependence on a previous understanding of biochemically defined genes and pathways. Thus, despite intensive investigation, it appears that only a small fraction of the variance found in human plasma lipoprotein levels can be explained by known genetic factors (10).

A third approach to the analysis of lipoprotein metabolism and other complex traits, termed quantitative trait locus mapping (QTL), ${ }^{1}$ has recently been developed using animal and plant models (11-14). The problems associated with genetic and environmental heterogeneity can be avoided through the use of animal models, and the development of numerous informative genetic markers in several animal species has made it feasible to analyze all regions of the mammalian genome. Excellent rodent models for several traits relevant to atherosclerosis are now available, including type 1 diabetes, type 2 diabetes, obesity, autoimmune disease, and hypertension (15). Genetic studies with these models have resulted in the identification of new chromosomal loci contributing to type 1 diabetes (16), obesity (17-19), and hypertension (20, 21). Similar genome-wide searches can be performed for complex traits in humans, although there are additional complications for linkage and for subsequent gene identification (14).

We now report the analysis of genetic factors for lipoprotein metabolism using a complete linkage map approach in the mouse. A cross between two inbred strains of mice, which differ strikingly in several lipoprotein parameters, was analyzed with respect to plasma lipoprotein and apolipoprotein levels on both a normal chow diet and an atherogenic diet high in fat and cholesterol. The results suggest possible functions for several known candidate genes and demonstrate the existence of several novel genetic loci not corresponding to any previously identified

1. Abbreviations used in this paper: QTL, quantitative trait locus; RFLV, restriction fragment length variations; TG, triglyceride. 
genes. We have examined in detail the expression of one candidate gene, apolipoprotein AII (apoAII), which exhibited very significant linkage to both plasma apoAII protein levels and HDL cholesterol levels.

\section{Methods}

Animals and diets. SM/J (SM) and NZB/B1NJ (NZB) mice were obtained from The Jackson Laboratory (Bar Harbor, ME). NZB females were mated with SM males to produce the F1 progeny, and the F2 animals were produced through brother sister matings among the F1 animals. After weaning at $21 \mathrm{~d}$, mice were individually housed in plastic cages with free access to food and water throughout the course of the study. All animals, parental as well as F1 and F2, were initially maintained on a normal chow diet (Purina 5001 chow) containing $4.5 \%$ fat. Plasma samples were collected at ages ranging from 3 to 5 mo and after a 12-h fast. All mice were then fed a moderate fat, high cholesterol diet (Teklad 90221; Teklad Premier Laboratory Diets, Madison, WI), containing $30 \%$ of calories as fat (22). The diet contains by weight $7.5 \%$ cocoa butter, $1.25 \%$ cholesterol, and $0.5 \%$ cholic acid with a total fat content of $15 \%$. Plasma samples were collected after $5 \mathrm{wk}$. Other methods were as described previously (23).

Lipoprotein measurements. Plasma total cholesterol, HDL, triglyceride (TG), and free fatty acid (FFA) concentrations were determined by enzymatic methods using colorimetric end points, essentially as previously described (23).

Plasma lipoproteins from pooled plasma samples from NZB and SM were fractionated using an FPLC system (Pharmacia LKB Biotechnology, Piscataway, NJ) with two Superose 6 columns in series. 0.5$\mathrm{ml}$ fractions were collected at a rate of $0.5 \mathrm{ml} / \mathrm{min}$ (24). Cholesterol concentrations were determined in each fraction as described above.

Antibodies and immunoassays. Polyclonal rabbit anti-mouse apoAI and apoAII antibodies were generously provided by Dietrich Machleder (UCLA). Gel-purified apoAI and apoAII protein samples were supplied by Dr. Renee LeBoeuf (University of Washington, Seattle, WA). Polyclonal rabbit anti-mouse apoAIV was obtained by constructing a TrpEAIV fusion protein. A 1.3-kb SmaI-HindIII mouse apoAIV cDNA fragment was ligated into the polylinker site of the pATH20 vector (25) immediately downstream of the TrpE gene. The reading frame between TrpE and AIV was maintained such that transcription and translation of the plasmid construct would yield a TrpE-apoAIV fusion protein. The plasmid was transformed into RR1 Escherichia coli cells which were treated with indoleacrylic acid to induce expression of TrpE. Cells were harvested and lysed, and the proteins were separated on an SDSPAGE gel. The fusion protein was isolated from the gel and used to immunize rabbits.

Plasma apolipoprotein concentrations were determined by immunoassays modified from those described previously (26). apoAII immunoblots were prepared by electrophoresis of diluted plasma samples through SDS polyacrylamide gels ( $15 \%$ acrylamide) followed by electroblotting onto Hybond ECL membranes (Amersham Corp., Arlington Heights, IL) in $20 \mathrm{mM}$ Tris, $150 \mathrm{mM}$ glycine, $\mathrm{pH} 8.3$ (TBS), at $11 \mathrm{~V}$ for $0.4 \mathrm{~h}$. apoAI and apoAIV levels were determined by a slot blot procedure in which samples, diluted 100 -fold in TBS (10 mM Tris, $0.9 \% \mathrm{NaCl}$ ), were applied to Hybond ECL membranes under vacuum followed by washing with $\sim 1 \mathrm{ml}$ TBS. Blots were allowed to air dry for $30 \mathrm{~min}$, treated with $15 \% \mathrm{H}_{2} \mathrm{O}_{2}$ for $15 \mathrm{~min}$ to reduce background, and blocked for $24 \mathrm{~h}$ at $4^{\circ} \mathrm{C}(10 \%$ Carnation instant milk in TBS with $0.5 \%$ Tween-20). The blots were then incubated with primary antibody solution, diluted either 1:2,500 (apoAII and apoAIV) or 1:7,500 (apoAI) in $1 \%$ milk, $0.1 \%$ Tween-20, for $12-24 \mathrm{~h}$ at room temperature with gentle shaking. Blots were washed in TBS, $0.3 \%$ Tween-20, incubated for 1-4 h with secondary antibody solution (1\% milk in TBS, $0.1 \%$ Tween-20, 1:7,500 dilution of ECL anti-rabbit IgG), and washed several times in TBS $0.3 \%$ Tween-20. Apolipoproteins were detected using a chemiluminescent procedure (Amersham ECL system) and quantitation was by densitometric measurement against a C57BL/6J pooled plasma standard of known protein concentration using a densitometer (SciScan model 5000; United States Biochemical, Cleveland, $\mathrm{OH})$. Samples were measured in quadruplicate and expressed as milligrams of protein per deciliter. The protocol was demonstrated to be linear for the concentrations of apolipoproteins present within the range of samples tested.

Genotypic analysis. Genomic DNA was isolated from mouse organs (kidney, lung, and liver) as described previously (23). Genotyping was done primarily by PCR amplification of microsatellite markers (27, 28) using PCR primer pairs (MapPairs ${ }^{\mathrm{TM}}$ ) purchased from Research Genetics (Huntsville, AL). Primer pairs were tested for polymorphic bands between the SM and NZB parent strains (data not shown).

The Apoa 2 gene marker was typed by Southern analysis using a mouse apoAII cDNA probe (26). DNA from NZB and SM parental strains was tested for restriction fragment length variations (RFLV) using 20 enzymes (AvaII, BamHI, BglII, DraI, EcoRI, EcoRV, HaeIII, HincII, HindIII, Hinf I, KpnI, MspI, PstI, PvuII, RsaI, SacI, SstI, TaqI, XbaI, and XmnI). RsaI revealed the only RFLV, with strain SM exhibiting a 1.4-kb band, NZB a 1.8-kb band, and F1 mice both bands. F2 mice were scored by digesting $5 \mu \mathrm{g}$ of genomic DNA with RsaI, followed by Southern analysis as described previously (23).

Statistical analysis. Phenotypic values are presented as the mean \pm standard error (SE) of the mean. ANOVA, regression analysis, and correlation analysis were performed using the Statview II $^{\mathrm{TM}}$ (Abacus Concepts Inc., Berkeley, CA) application for the Macintosh computer. Linkage analysis among the microsatellite markers used was performed using the MAPMAKER program (29), with genetic distances reported as recombination fractions. The MAPMAKER/QTL program (provided by S. Lincoln and E. Lander, Massachusetts Institute of Technology, Cambridge, MA) was used for QTL analysis as described for F2 intercrosses $(11,12)$. Phenotypes were normalized using the $\log$ (trait) function or by correcting the data for age and sex differences among the $\mathrm{F} 2$ animals. A lod score $\geq 3$ but $<5$ was considered to be suggestive for linkage, and a lod score of 5 or greater was considered to be significant (see Discussion).

Northern analysis. Total liver RNA was isolated from NZB and SM mice kept on a normal chow diet and a high fat diet (30). $10 \mu \mathrm{g}$ of each RNA sample was analyzed by Northern blotting as described previously ( 31 ). The blots were probed with an apoAII cDNA fragment (26). The blots were then stripped and rehybridized with either an $18 \mathrm{~s}$ or 28s rRNA cDNA to normalize the signal. A total of 8 SM and 10 NZB mice were examined.

Rates of protein synthesis measurements. The relative rates of apoAII protein synthesis were determined for chow-fed NZB and SM parental animals using $\left[{ }^{35} S\right]$ methionine incorporation into freshly isolated hepatocytes (26). Separate hepatocyte isolates were obtained from three NZB females and two SM females. Aliquots of cells at times 0 , 6,12 , and $18 \mathrm{~min}$ after the addition of $\left[{ }^{35} \mathrm{~S}\right]$ methionine for each animal were lysed. Each aliquot was immunoprecipitated with a rabbit antiapoAII antiserum. The immunoprecipitated aliquots were then reimmunoprecipitated with the anti-apoAII antiserum to ensure complete recovery of the apoAII. The immunoprecipitates were electrophoresed on a $14 \%$ acrylamide gel followed by fluorography (26). Radioactivity incorporated into apoAII was determined by excising the appropriate regions of the dried gels and counting by liquid scintigraphy. The apoAII counts were normalized to the total protein synthesized for each time point.

Sequence analysis of apoAII mRNA. The cDNA strand was synthesized from total liver RNA isolated from parental NZB and SM animals using Moloney murine leukemia virus reverse transcriptase in a 50- $\mu \mathrm{l}$ reaction containing $5 \mu \mathrm{g}$ of RNA and oligo(dT). $5 \mu \mathrm{l}$ of the cDNA reaction was PCR amplified in $100 \mu \mathrm{l}$ of buffer ( $10 \mathrm{mM}$ Tris, pH 8.3, $50 \mathrm{mM} \mathrm{KCl}, 0.01 \%$ gelatin, $6.7 \mathrm{mM} \mathrm{MgCl}_{2}, 5 \% \mathrm{DMSO}$, and $2.5 \mathrm{mM}$ dNTPs) using Thermus aquaticus polymerase. The sequences of the amplification primers were based upon previously determined sequences of apoAII (26). The sequence of the 5' primer was 5'-GAATTCCATAGAATCGCAGCACTGTTCCT $-3{ }^{\prime}$. and the sequence of the $3^{\prime}$ primer was $5^{\prime}$-GAATTCAACTCCTTCCGCATTTATT- $3^{\prime}$ '. 30 cycles of ampli- 
fication were carried out. The denaturation step was performed at $95^{\circ} \mathrm{C}$ for $1 \mathrm{~min}$; the annealing step was performed at $45^{\circ} \mathrm{C}$ for $1 \mathrm{~min}$ for the first five cycles, and at $55^{\circ} \mathrm{C}$ for $30 \mathrm{~s}$ for the subsequent 25 cycles; extension was carried out at $72^{\circ} \mathrm{C}$ for $1.5 \mathrm{~min}$ for all 30 cycles. The products were purified and isolated from a $0.8 \%$ agarose gel. The isolated apoAII PCR products from NZB and SM were sequenced by thermal cycle sequencing and were analyzed by an automated fluorescence sequencer. Both strands of both products were sequenced using the above-mentioned primers.

\section{Results}

Lipoprotein phenotypes of parental strains NZB/BINJ and SM/ $J$. Strains NZB and SM were chosen for construction of a genetic intercross because of their marked differences in lipoprotein levels (23) and fatty streak lesion development (32). We characterized these strains for plasma levels of total cholesterol, HDL cholesterol, LDL plus VLDL cholesterol, triglycerides, and apolipoproteins AI, AII, and AIV on both a normal chow diet and an atherogenic diet rich in fat and cholesterol (Table I). The atherogenic diet has been shown to produce fatty streak lesions in "susceptible" strains of mice, including SM, but not in "resistant" strains such as NZB. Plasma lipoproteins for SM and NZB were subjected to gel filtration analysis (Fig. 1).

On a chow diet, the total plasma cholesterol levels for strain NZB $(166 \mathrm{mg} / \mathrm{dl})$ were about 2.5 -fold greater than those of strain SM $(68 \mathrm{mg} / \mathrm{dl})$. The bulk of this difference was due to HDL cholesterol levels which were $146 \mathrm{mg} / \mathrm{dl}$ in NZB and only $59 \mathrm{mg} / \mathrm{dl}$ in SM. The levels of LDL plus VLDL cholesterol in NZB mice $(20 \mathrm{mg} / \mathrm{dl})$ were also significantly elevated as compared with SM animals $(9 \mathrm{mg} / \mathrm{dl})$, whereas the levels of triglycerides and free fatty acids were similar (Table I). The levels of apoAI, the major protein of HDL, were only slightly higher in strain NZB $(123 \mathrm{mg} / \mathrm{dl})$ than for SM $(98 \mathrm{mg} / \mathrm{dl})$, suggesting that the HDL of NZB mice carry more cholesterol per particle than those of SM mice. This is supported by the results of gel filtration analysis which show that the HDL particles of NZB mice are larger than SM HDL (Fig. 1). The levels of apoAII, the second most abundant HDL protein, differed dramatically between strains, with NZB exhibiting about a 10fold greater plasma apoAII level as compared with SM ( 21 and $2 \mathrm{mg} / \mathrm{dl}$, respectively). The levels of apoAIV, a protein which also resides on HDL particles, as well as the more triglyceriderich lipoproteins, were very similar between the two strains (Table I).

When maintained for 5 wk on a high fat diet, both strains exhibited large increases in their LDL plus VLDL cholesterol. There was an $\sim 25 \%$ fall in the HDL values for the SM mice on the high fat diet, whereas there was no significant change in HDL levels with diet in the NZB mice. However, the NZB males exhibited a small increase and the NZB females a small decrease in HDL values when placed on the high fat diet. In strain NZB, the LDL plus VLDL levels increased $\sim 8$-fold as compared with the chow diet, whereas in strain SM the increase was substantially greater, $\sim 33$-fold, providing a striking example of the genetic control governing the response to dietary challenge. On the high fat diet, the ratio of LDL plus VLDL cholesterol to HDL cholesterol was significantly greater in SM mice $(\sim 6: 1)$ as compared with NZB mice $(\sim 1: 1)$. The levels of triglycerides, free fatty acids, apoAI, and apoAII remained fairly constant on the two diets, whereas the levels of apoAIV increased about twofold in both strains (Table I).
Table I. Parental Strain Phenotypes

\begin{tabular}{|c|c|c|c|c|c|}
\hline Diet & Sex & SM & NZB & SM & NZB \\
\hline & & \multicolumn{2}{|c|}{ Total cholesterol } & \multicolumn{2}{|c|}{ HDL cholesterol } \\
\hline \multirow[t]{3}{*}{ Chow } & $\mathbf{M}$ & $77 \pm 6$ & $174 \pm 3$ & $68 \pm 3$ & $154 \pm 1$ \\
\hline & $F$ & $54 \pm 10$ & $155 \pm 4$ & $58 \pm 10^{*}$ & $136 \pm 2$ \\
\hline & B & $68 \pm 7$ & $166 \pm 4$ & $63 \pm 10^{\ddagger}$ & $146 \pm 3$ \\
\hline \multirow[t]{4}{*}{ High fat } & $\mathbf{M}$ & $292 \pm 44$ & $326 \pm 4$ & $49 \pm 6$ & $175 \pm 8$ \\
\hline & $\mathrm{F}$ & $369 \pm 64$ & $284 \pm 24$ & $44 \pm 6^{*}$ & $112 \pm 4$ \\
\hline & B & $325 \pm 32$ & $308 \pm 12$ & $46 \pm 6^{\ddagger}$ & $147 \pm 12$ \\
\hline & & \multicolumn{2}{|c|}{$L D L+V L D L$} & \multicolumn{2}{|c|}{ apoAII } \\
\hline \multirow[t]{3}{*}{ Chow } & $\mathbf{M}$ & $10 \pm 3$ & $20 \pm 3$ & $2.2 \pm 0.3$ & $21.9 \pm 8.1$ \\
\hline & $\mathrm{F}$ & $8 \pm 4$ & $19 \pm 2$ & $1.4 \pm 0.2$ & $19.6 \pm 4.3$ \\
\hline & B & $9 \pm 2$ & $20 \pm 2$ & $1.9 \pm 0.2$ & $20.9 \pm 0.4$ \\
\hline \multirow[t]{4}{*}{ High fat } & $\mathbf{M}$ & $244 \pm 48$ & $152 \pm 4$ & $2.8 \pm 0.4$ & $15.7 \pm 5.2$ \\
\hline & $F$ & $363 \pm 42$ & $172 \pm 27$ & $1.5 \pm 0.5$ & $14.7 \pm 4.7$ \\
\hline & B & $295 \pm 39$ & $161 \pm 12$ & $2.2 \pm 0.3$ & $15.3 \pm 0.2$ \\
\hline & & \multicolumn{2}{|c|}{ apoAIV } & \multicolumn{2}{|c|}{ apoAI } \\
\hline \multirow[t]{3}{*}{ Chow } & $\mathbf{M}$ & $4.6 \pm 0.4$ & $3.5 \pm 0.4$ & $114 \pm 12$ & $124 \pm 6$ \\
\hline & $F$ & $4.0 \pm 0.1$ & $3.6 \pm 0.3$ & $77 \pm 7$ & $122 \pm 6$ \\
\hline & B & $4.3 \pm 0.2$ & $3.5 \pm 0.2$ & $98 \pm 10$ & $123 \pm 4$ \\
\hline \multirow[t]{4}{*}{ High fat } & $\mathbf{M}$ & $8.0 \pm 0.2$ & $5.9 \pm 0.3$ & $112 \pm 6$ & $150 \pm 11$ \\
\hline & $\mathbf{F}$ & $7.5 \pm 1.0$ & $5.0 \pm 0.4$ & $53 \pm 3$ & $122 \pm 9$ \\
\hline & B & $7.8 \pm 0.4$ & $5.5 \pm 0.3$ & $87 \pm 12$ & $140 \pm 9$ \\
\hline & & \multicolumn{2}{|c|}{$T G$} & \multicolumn{2}{|c|}{$F F A$} \\
\hline \multirow[t]{3}{*}{ Chow } & $\mathbf{M}$ & $30 \pm 5$ & $39 \pm 2$ & $22 \pm 3$ & $27 \pm 2$ \\
\hline & $\mathrm{F}$ & $31 \pm 6$ & $44 \pm 3$ & $28 \pm 5$ & $27 \pm 2$ \\
\hline & B & $31 \pm 6$ & $41 \pm 2$ & $25 \pm 3$ & $27 \pm 1$ \\
\hline \multirow[t]{3}{*}{ High fat } & $\mathbf{M}$ & $27 \pm 1$ & $49 \pm 3$ & $31 \pm 1$ & $40 \pm 2$ \\
\hline & $\mathrm{F}$ & $37 \pm 1$ & $47 \pm 2$ & $37 \pm 2$ & $39 \pm 2$ \\
\hline & B & $31 \pm 2$ & $48 \pm 2$ & $33 \pm 1$ & $39 \pm 1$ \\
\hline
\end{tabular}

Values are given for males $(M)$, females $(F)$, or both sexes combined $(B)$. All data are expressed as milligrams per deciliter of plasma, mean value \pm standard error (SE), on a normal chow diet and after $5 \mathrm{wk}$ on a high fat (hf) diet. Significant differences by sex were found via ANOVA for HDL cholesterol levels in both strains: SM (chow) $P=0.0280$, SM (hf) $P=0.0017$, NZB (chow) $P=0.0002$, NZB (hf) $P=0.0003$, and also for apoAI levels in the SM parent only (chow) $P=0.0564$, (hf) $P=0.0007$. All other $P$ values were $>0.05$. Sample sizes: $\operatorname{SM} n=7$, with SM females $n=3$ and SM males $n=4$; NZB $n=9$, with NZB females $n=4$ and NZB males $n=5$. * These results were obtained from a separate experiment. $n=5$ for HDL values from female SM mice on chow, and $n=6$ for HDL values of SM mice on high fat diet. ${ }^{\ddagger}$ These parental strain results are an estimate obtained from averaging the male and female results shown above.

In general, female mice are more prone to developing aortic fatty streak lesions when maintained on the high fat diet than are male mice (32), and previous studies have also revealed a number of gender differences for lipoprotein levels in mice (24, $33,34)$. In this study, females tended to have lower levels of HDL cholesterol and apoAI on both chow and high fat diets and slightly elevated levels of LDL plus VLDL cholesterol on the high fat diet (Table I). All other parameters measured were similar in both males and females.

Inheritance of lipoprotein phenotypes. The distribution of 


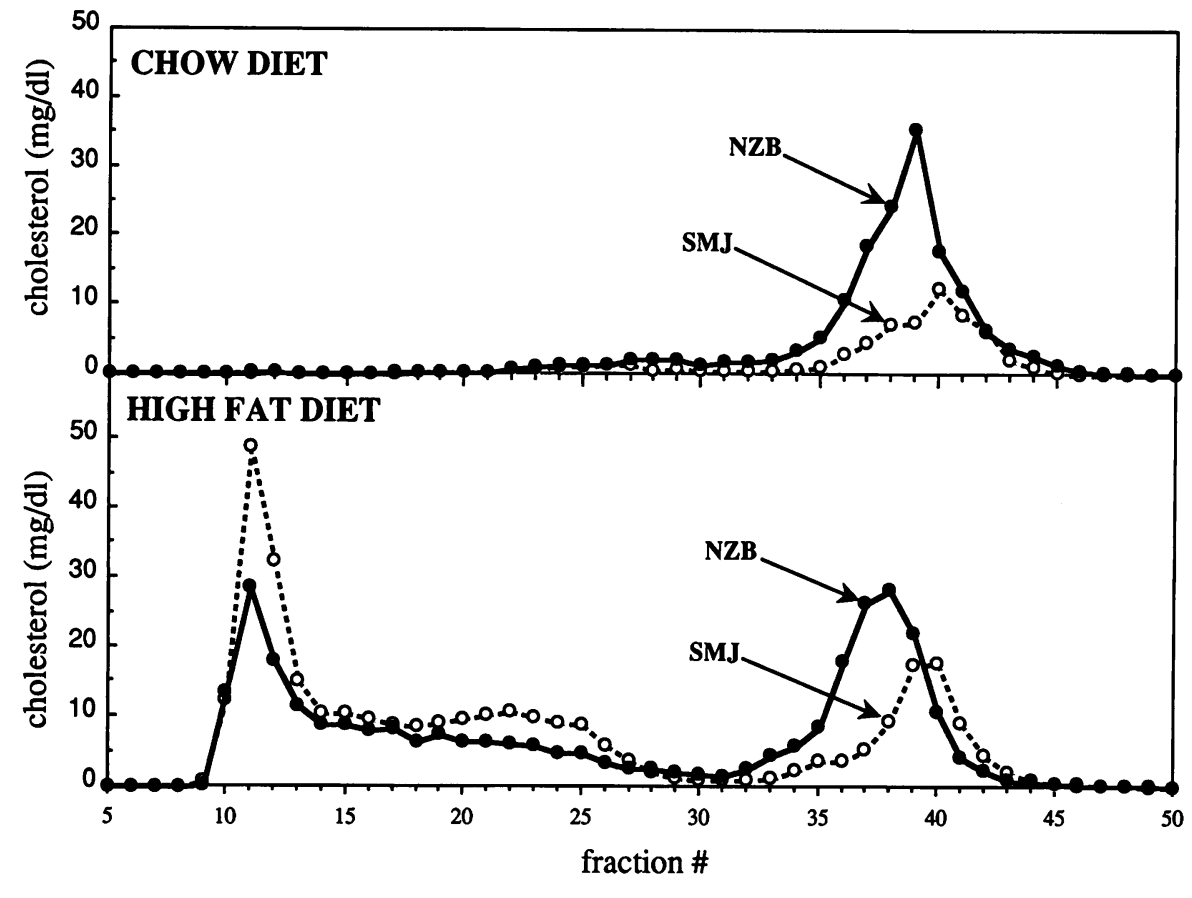

Figure 1. Gel filtration analysis of plasma lipoproteins. Pooled plasma samples from NZB and SM were separated according to size by FPLC using two Superose columns in series. $400 \mu \mathrm{l}$ of pooled plasma was applied to the column for each separation. Cholesterol concentrations were measured for each 0.5 -ml fraction. In such separations, VLDL and large IDL particles elute near the void volume (fractions 10-13), followed by smaller IDL and LDL particles (fractions 14 30), and, lastly, HDL (fractions 31-44).

plasma lipid and apolipoprotein levels among $184($ NZB $\times$ SM) F2 progeny is shown in Fig. 2. The broad range of lipid levels reflects the large differences in the parental strains. For HDL and apoAII, values which differed dramatically in the parents, the majority of F2 animals showed values between the parental extremes. For LDL plus VLDL, many individuals had values

A $\begin{array}{ccc}\text { Total } & \text { HDL } & \text { LDL + VLDL } \\ \text { Cholesterol } & \text { Cholesterol } & \text { Cholesterol }\end{array}$ Triglycerides $\begin{gathered}\text { Free Fatty } \\ \text { Acids }\end{gathered}$

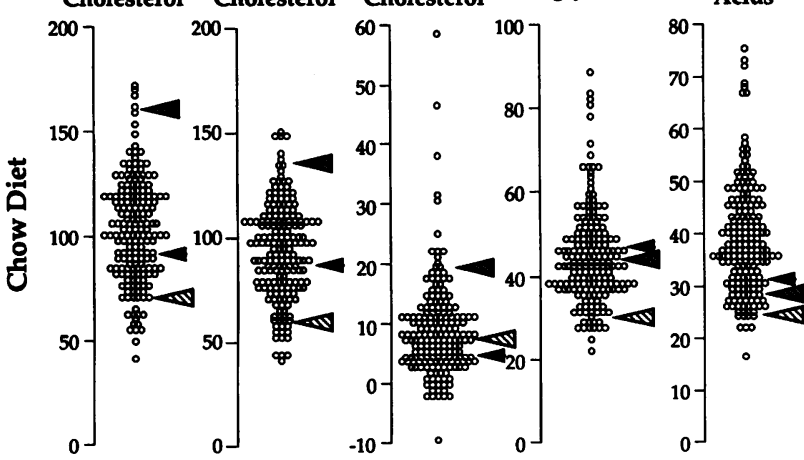

$\mathbf{B}$
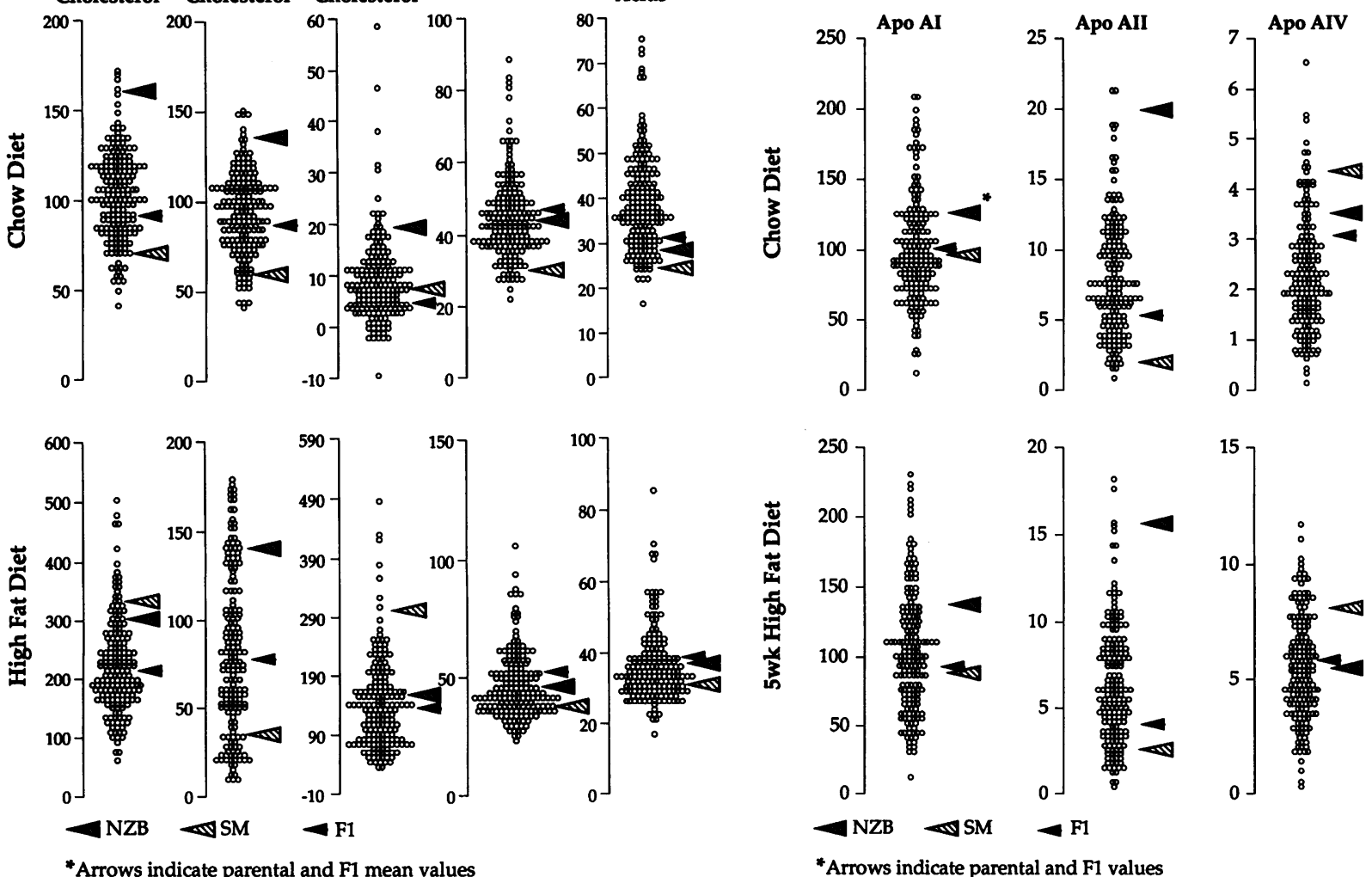

*Arrows indicate parental and F1 mean values

*Arrows indicate parental and F1 values

Figure 2. Distribution of plasma lipid $(A)$ and apolipoprotein $(B)$ values among the F2 progeny animals. All values are expressed as milligrams per deciliter. Maximum scale limits are not equal between categories in order to adequately illustrate the range of phenotypes. The levels of LDL + VLDL were calculated by subtraction of HDL from total cholesterol, so the values $<0$ reflect experimental error in the assays. Parental and F1 values are indicated. 
Table II. Strength of Association between Plasma Lipoprotein and Apolipoprotein Values in $(N Z B \times S M)$ F2 Animals

\begin{tabular}{lcccccrrr}
\hline & Total cholesterol & HDL & LDL + VLDL & TG & FFA & apoAI & apoAII & apoAIV \\
\hline Total cholesterol & & $0.95^{*}$ & $0.46^{*}$ & $0.31^{*}$ & 0.02 & 0.25 & $0.43^{*}$ & -0.20 \\
HDL cholesterol & $0.43^{*}$ & & 0.21 & $0.32^{*}$ & 0.10 & 0.25 & $0.47^{*}$ & -0.18 \\
LDL + VLDL cholesterol & $0.78^{*}$ & -0.17 & & 0.20 & -0.16 & 0.16 & -0.01 & -0.08 \\
TG & $0.38^{*}$ & $0.72^{*}$ & -0.04 & & $0.66^{*}$ & 0.13 & 0.06 & -0.02 \\
FFA & 0.24 & $0.45^{*}$ & -0.01 & $0.66^{*}$ & & -0.01 & 0.06 & 0.19 \\
apoAI & $0.36^{*}$ & $0.62^{*}$ & -0.004 & $0.49^{*}$ & $0.32^{*}$ & 0.06 & -0.06 \\
apoAII & $0.39^{*}$ & $0.63^{*}$ & .002 & $0.47^{*}$ & $0.35^{*}$ & $0.38^{*}$ & -0.16 \\
apoAIV & -0.01 & -0.17 & 0.09 & -0.11 & 0.07 & 0.10 & -0.16 & \\
\hline
\end{tabular}

Strength of association expressed as Spearman's rho between quantitative measures of plasma lipoprotein and apolipoprotein values in (NZB $\times$ SM) F2 animals. Values to the top right of the diagonal are Spearman rank correlation coefficients (rho) for phenotypes measured on a chow diet, and values to the bottom left are correlation coefficients for phenotypes after $5 \mathrm{wk}$ on a high fat diet. Using the formula for the adjusted level of significance $=0.1 /(2 \times$ No. of comparisons $)$ with a total of 64 comparisons, the required $P$ value for significance was calculated to be $<0.0008$. Correlations significant at this level are indicated by an asterisk.

far above and below the parent range, as is also reflected in the total cholesterol levels, particularly on the high fat diet. TG, FFA, apoAI, and apoAIV levels in the F2 animals were distributed well outside the parent strain ranges as well, indicative of the recombining of genetic components in the F2 mice which result in a wide range of phenotypes.

Several phenotypic correlations were observed in the F2 animals (Table II). Total cholesterol levels were very strongly correlated with HDL cholesterol levels on a chow diet $(r$ $=0.95)$ and with LDL plus VLDL on a high fat diet $(r=0.78)$. The two major proteins associated with HDL, apoAI and apoAII, both demonstrated strong positive correlations with HDL levels. However, the levels of apoAI and apoAII on a chow diet were only poorly correlated with each other, suggesting that these proteins are regulated independently. The levels of triglycerides were positively correlated with the levels of HDL cholesterol on both chow $(r=0.32)$ and high fat $(r$ $=0.72)$ diets. These correlations suggest interactions between the metabolism of triglyceride-rich lipoproteins and HDL, but they contrast with results found in human studies which indicate negative correlations between triglyceride and HDL levels (3).

Identification of genetic loci contributing to plasma lipoprotein and apolipoprotein levels. We attempted to type genetic markers in the (NZB $\times$ SM) F2 mice at intervals of 20 centimorgans $(\mathrm{cM})$ or less throughout the 1,500 -cM mouse genome to test for linkage to lipoprotein traits. Since the number of loci contributing to lipoprotein variations between the parental strains is unknown, we chose to construct a relatively dense map, such that the underlying genes would be $10 \mathrm{cM}$ or less from a typed genetic marker, to maximize the power for detection of linkage. Highly polymorphic simple sequence repeat (microsatellite) markers (28) were tested for polymorphisms between the parental strains, and informative markers (about half of those tested) were used to type the $184($ NZB $\times$ SM) F2 progeny. Altogether, 125 microsatellite markers spanning all 20 chromosomes (excluding the Y) were typed. The resulting linkage map is shown in Fig. 3. Due to a failure in some cases to identify informative markers, gaps in the linkage map of $>20 \mathrm{cM}$ are present within a small number of chromosomal regions. Because many of the markers were previously mapped in only a small number of progeny from genetic crosses, re- sulting in large uncertainty in the locations of the markers, the map is in many areas much denser than anticipated.

We searched for genetic loci underlying the lipoprotein traits measured in the F2 mice by statistical analysis using the MAPMAKER/QTL program (11). The strength of association between genotypes at each locus and of the phenotype under investigation is expressed as the $\log _{10}$ of the likelihood of the odds-ratio, or "lod" score. Simulation studies suggest that for the density of markers scored in our cross, a lod score of $\sim 3$ or greater is statistically significant, indicating a high probability of linkage (11). As discussed below, however, this threshold should be increased because multiple traits were examined. The MAPMAKER/QTL program calculates lod scores at 2-cM intervals between markers by estimating the most likely genotype at each interval. Peak lod scores indicate the most likely locations of genes contributing to the lipoprotein traits measured.

Suggestive or significant lod scores $(>3.0)$ observed in the F2 mice are listed in Table III. Plots of lod score values versus genetic markers are presented for the loci exhibiting the largest peak lod scores $(>5.0)$ in Figs. 4-6. Five loci were identified for total cholesterol levels, three for HDL cholesterol levels, four for LDL + VLDL cholesterol levels, three for triglyceride levels, three for free fatty acid levels, and three for apoAII levels (D1Mit36, and two loci on chromosome 5 using D5Mit61 and D5Mit43). No loci with significant effects on apoAI levels or apoAIV levels were observed. Some loci exhibited gender differences, where the effects of a particular locus on a phenotypic trait was much stronger in one sex than in the other. These included loci on chromosome 5 for total cholesterol, HDL cholesterol, and apoAII levels, on chromosome 9 for LDL+VLDL cholesterol levels, and on chromosome 1 for free fatty acid levels (Table III). Several of the observed linkages were also specific for only one of the two diets studied. In particular, three out of four loci observed for LDL + VLDL cholesterol levels and all of the loci observed for triglyceride and free fatty acid levels were specific for the high fat diet.

The strongest linkages were observed for the distal region of chromosome 1, which contained coincidental lod score peaks for plasma HDL cholesterol and apoAII levels (Table IV). This chromosomal region contains the apoAII structural gene (designated Apoa2), suggesting that genetic variations of this 

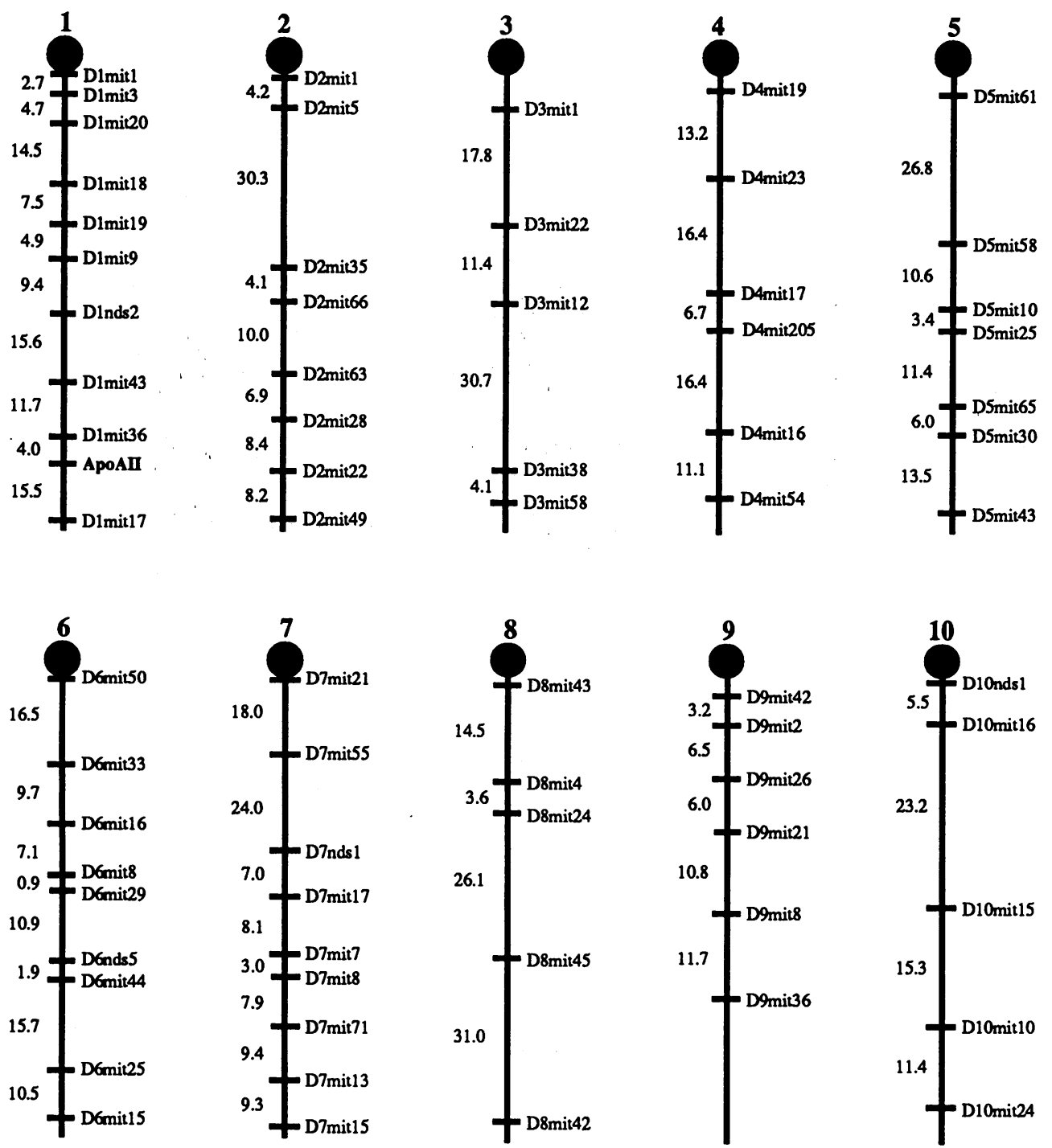

Figure 3. Complete linkage map of 126 microsatellite and cDNA markers typed in the NZB $\times$ SM cross. Distances between markers (indicated to the left of the chromosomes) were calculated by the MAPMAKER computer program (29) as percent recombination (centimorgans). Chromosomes were not drawn to scale. $(A)$ Chromosomes 1-10; $(B)$ chromosomes 11-19 and X. The Y chromosome was not typed.

gene determine apoAII levels which then influence HDL cholesterol levels. We have further examined this possible mechanism at the molecular level (see below).

Chromosome 5 contained additional coincidental loci for total cholesterol levels on a chow diet (lod score 6.7), HDL cholesterol levels on a chow diet (lod score 5.3), and HDL cholesterol levels on a high fat diet (lod score 5.6). The fact that the peak lod scores were found in a similar region of the chromosome (between markers D5Mit25 and D5Mit30) suggests that a single gene is responsible for the three traits. Interestingly, while this gene influenced HDL cholesterol levels in both males and females, its effect was much more pronounced in females. For example, in the instance of HDL cholesterol levels on a high fat diet, the calculated lod score at marker D5Mit 25 was 4.6 for females and only 2.2 for males. A similar large difference between sexes was observed using either total cholesterol or HDL cholesterol levels on a chow diet. In this regard it is noteworthy that the HDL cholesterol levels varied significantly between males and females of the parental strains (Table I). This region of chromosome 5 does not correspond to any previously mapped candidate genes, such as apolipoproteins, lipases, enzymes that mediate lipid synthesis and transport, or lipoprotein receptors (35). Table IV shows the levels of total cholesterol and HDL cholesterol levels by genotype at the D5Mit25 locus. When male and female values were considered together (Table IV, top), it was clear that the NZB and $\mathrm{SM}$ alleles at this locus exhibited additive inheritance since the heterozygote (NS) values were intermediate to those for the homozygotes (NN or NS). Consistent with the gender differences seen previously for these traits (Table I), when male and female values were considered separately (Table IV, bottom), the levels of both total cholesterol and HDL cholesterol were significantly lower in the females.

Three of the four loci for LDL + VLDL cholesterol levels were observed only on a high fat diet, perhaps reflecting the relatively low levels of LDL and VLDL present on a chow diet. The loci on chromosomes 12 and 15 do not correspond to any obvious candidate genes, whereas the peak lod score for the chromosome 9 locus (between markers D9Mit2 and D9Mit26) is near the apoAI-CIII-AIV gene cluster and the LDL receptor 

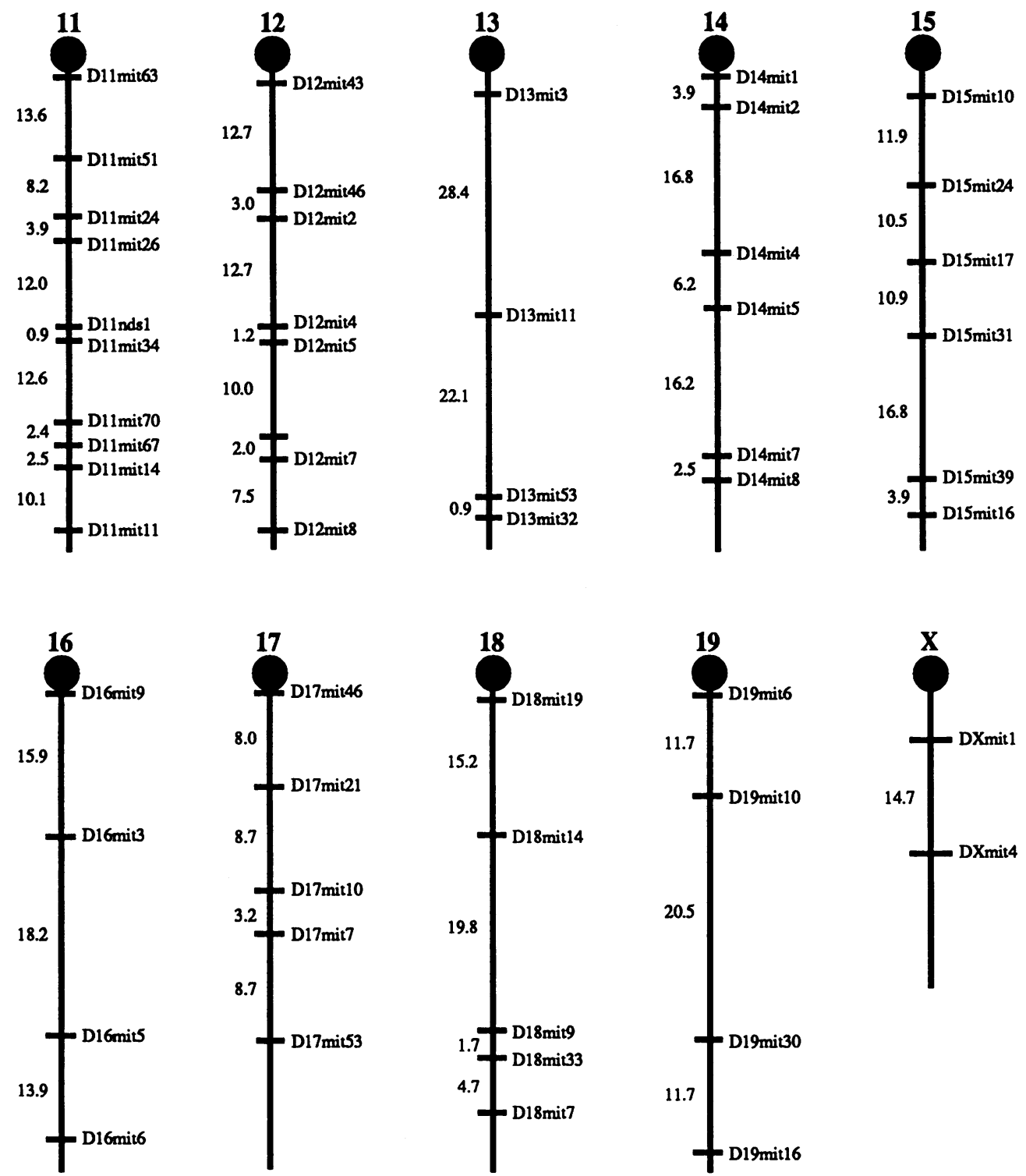

Figure 3 (Continued)

gene and the peak lod score for the chromosome 13 locus (around marker D13Mit11) is near the hydroxymethylglutarylcoenzyme A (HMG-CoA) reductase gene (35). The linkages on chromosomes 9 and 12 were observed primarily in males, with lod scores $<1.1$ for females, whereas the linkages on chromosomes 13 and 15 were about equally strong in both sexes (Table III). It is noteworthy that significant differences in LDL + VLDL levels on a high fat diet were observed between male and female SM mice (Table I). Together, the chromosome 9 , 12, and 15 loci explain $>40 \%$ of the variance of LDL+VLDL cholesterol levels on the high fat diet (Table III).

A locus on the proximal region of chromosome 7 exhibited strong linkage with total plasma triglyceride levels (lod 5.1) and free fatty acid levels (lod 5.6) in mice maintained on a high fat diet but not on a chow diet (Fig. 5). The loci coincided almost precisely, suggesting that they result from a single gene located near the D7Mit55 marker. This marker resides near the genes for hormone-sensitive lipase and the apoE-CI-CII gene cluster, candidate genes which could influence triglyceride and free fatty acid metabolism (see Discussion).

Linkage of apoAII levels and HDL cholesterol levels to a chromosome 1 locus is explained by apoAII gene variation. As discussed above, the levels of apoAII and HDL cholesterol were linked in F2 mice to a region of chromosome 1 containing the apoAII structural gene (designated Apoa2). To test whether genetic variations of Apoa2 are responsible for the linkage results, we precisely mapped the Apoa 2 gene in the region. Southern analysis was used to screen 20 different restriction enzymes to identify RFLV for Apoa2 between the parental strains. One enzyme, RsaI, revealed an informative RFLV. Thus, when DNA from the parental strains was digested with RsaI and subjected to Southern analysis using an apoAII cDNA hybridization probe, strain NZB mice exhibited a 1.8 -kb band whereas strain SM mice exhibited a 1.4-kb band. This RFLV was typed in 179 
Table III. Lod Scores $>3.0$ Observed in $(N Z B \times S M) F 2$ Mice

\begin{tabular}{|c|c|c|c|c|c|c|c|}
\hline Trait & Diet & Adjustments & Nearest marker & Chromosome & Variance explained & Lod & $n$ \\
\hline \multirow{7}{*}{ Total cholesterol } & Chow & & DIMit36 & 1 & $16.1 \%$ & 5.9 & 170 \\
\hline & & & D5Mit25 & 5 & $17.1 \%$ & 6.7 & 174 \\
\hline & & Males & D18Mit7 & 18 & $15.0 \%$ & 3.2 & 95 \\
\hline & & & Apoa2 & 1 & $15.2 \%$ & 6.6 & 170 \\
\hline & High fat & Females & D5Mit30 & 5 & $20.4 \%$ & 4.0 & 77 \\
\hline & & Males & D12Mit5 & 12 & $21.2 \%$ & 4.1 & 88 \\
\hline & & $\log$ & D15Mit39 & 15 & $9.8 \%$ & 3.1 & 168 \\
\hline \multirow[t]{8}{*}{ HDL cholesterol } & Chow & & DIMit36 & 1 & $18.0 \%$ & 6.9 & 170 \\
\hline & & & D5Mit30 & 5 & $13.1 \%$ & 5.3 & 166 \\
\hline & & Females & D5Mit25 & 5 & $33.1 \%$ & 6.2 & 79 \\
\hline & & $\log$ & D17Mit21 & 17 & $11.7 \%$ & 4.4 & 156 \\
\hline & & & Apoa 2 & 1 & $17.8 \%$ & 8.1 & 170 \\
\hline & High fat & & DIMit36 & 1 & $5.8 \%$ & 3.2 & 165 \\
\hline & & & D5Mit25 & 5 & $10.4 \%$ & 5.6 & 167 \\
\hline & & & Apoa2 & 1 & $6.7 \%$ & 3.6 & 165 \\
\hline \multirow{4}{*}{ LDL + VLDL cholesterol } & Chow & & D13Mit11 & 13 & $7.7 \%$ & 3.1 & 166 \\
\hline & High fat & Males & D9Mit26 & 9 & $16.2 \%$ & 3.4 & 87 \\
\hline & & Males & D12Mit5 & 12 & $15.6 \%$ & 3.2 & 88 \\
\hline & & & D15Mit17 & 15 & $11.0 \%$ & 3.6 & 163 \\
\hline \multirow[t]{3}{*}{ TG } & High fat & $\log$ & $D 1 N d s 2$ & 1 & $11.6 \%$ & 3.5 & 150 \\
\hline & & & D5Mit65 & 5 & $5.7 \%$ & 3.2 & 161 \\
\hline & & $\log$ & D7Mit55 & 7 & $13.2 \%$ & 5.1 & 157 \\
\hline \multirow[t]{4}{*}{ FFA } & High fat & $\log$ & $D 1 N d s 2$ & 1 & $12.4 \%$ & 3.9 & 150 \\
\hline & & Females & DIMit17 & 1 & $16.9 \%$ & 3.0 & 65 \\
\hline & & $\log$ & D7Mit55 & 7 & $14.0 \%$ & 5.6 & 157 \\
\hline & & Males & D17Mit7 & 17 & $13.3 \%$ & 3.1 & 86 \\
\hline \multirow[t]{6}{*}{ apoAII } & Chow & $\log$ & D1Mit36 & 1 & $37.9 \%$ & 14.8 & 169 \\
\hline & & & D5Mit6I & 5 & $10.7 \%$ & 3.4 & 156 \\
\hline & & & Apoa2 & 1 & $41.5 \%$ & 19.6 & 169 \\
\hline & High fat & $\log$ & DIMit36 & 1 & $23.2 \%$ & 7.9 & 168 \\
\hline & & Females & D5Mit43 & 5 & $18.5 \%$ & 3.3 & 79 \\
\hline & & & Apoa2 & 1 & $23.3 \%$ & 10.3 & 168 \\
\hline
\end{tabular}

All values were calculated by the MAPMAKER/QTL program and have been adjusted to correct for differences due to both age and gender. Lod scores that were determined to be either male or female specific for a certain trait are indicated as such under the Adjustments column. In such cases, the peak lod scores for the opposite sex were all LOD $>1$ 1.1. For other traits, when the phenotypic values did not fall within a normal bellshaped curve, the log of the lod scores was plotted, resulting in a normalized curve that maximizes the peak lod score obtained. The peak lod scores before adjustment by $\log$ are as follows: total cholesterol (high fat) D15Mit39, lod $=2.6$ with $6.6 \%$ variance explained; HDL cholesterol (chow) $D 17 M i t 21, \operatorname{lod}=3.2$ with $9.5 \%$ variance explained; TG (high fat) $D 1 N d s 2$, lod $=2.8$ with $6.5 \%$ variance explained; TG (high fat) $D 7 M i t 55$, lod $=4.6$ with $8.3 \%$ variance explained; FFA (high fat) $D I N d s 2$, lod $=2.8$ with $7.9 \%$ variance explained; FFA (high fat) $D 7 M i t 55$, lod $=4.3$ with $9.7 \%$ variance explained; apoAII (chow) DIMit36, lod $=12.0$ with $28.2 \%$ variance explained; apoAII (high fat) $D 1 M i t 36$, lod $=6.3$ with $15.4 \%$ variance explained.

of the $\mathrm{F} 2$ progeny and allowed mapping of the Apoa2 gene to a region $4.0 \mathrm{cM}$ distal (with respect to the centromere) to DIMit36 and $15.5 \mathrm{cM}$ proximal to DlMitl7 (Fig. 3). This placed Apoa 2 precisely under the peak lod scores for plasma apoAII and HDL cholesterol levels (Fig. 3), supporting the possibility that variations of the Apoa2 gene contribute to apoAII and HDL cholesterol levels.

On a chow diet, the Apoa2 locus explained $\sim 42 \%$ of the variance in apoAII levels and $18 \%$ of the variance in HDL cholesterol levels (Table III). On the high fat diet, the effect of the Apoa 2 locus was reduced, explaining $23 \%$ of the variance in apoAII levels and $7 \%$ of the variance in HDL cholesterol levels. The effect of the Apoa2 locus on these traits is evident when average values for apoAII and HDL cholesterol levels within each of the three possible genotypes (homozygous for either the NZB or SM allele, and heterozygous) are calculated (Table V). For both traits and both diets, heterozygous animals exhibited intermediate values, indicating that the Apoa 2 locus exhibits additive inheritance (rather than recessive or dominant) with respect to apoAII and HDL cholesterol levels. The Apoa2 locus affects HDL cholesterol levels in both males and females, although on both diets females exhibit significantly lower HDL cholesterol levels than males (Table V).

Regression analysis was performed to examine the relation- 
Chromosome 5

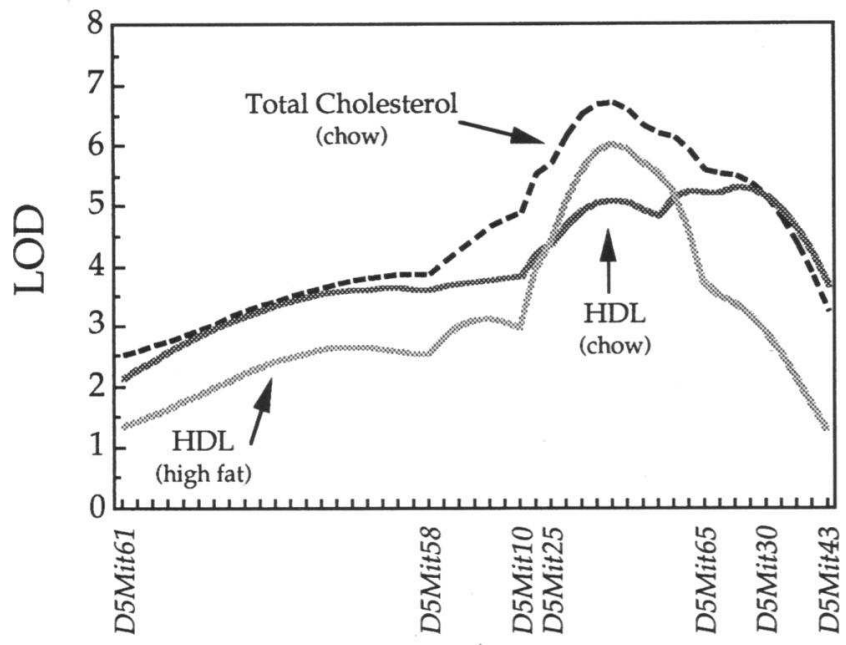

Figure 4. A locus on chromosome 5 which contributes to plasma total cholesterol and HDL cholesterol levels. The $x$-axis represents distances along chromosome 5 with D5Mit61 nearest to the centromere and D5Mit43 the most distal marker. Lod scores were calculated and plotted at 2-cM intervals, represented by ticks along the $x$-axis. For specific distances between markers, refer to Fig. $2 \mathrm{~A}$. All phenotypes were adjusted to correct for differences due to sex and age.

ship between the levels of apoAII and the levels of HDL cholesterol (Table II). The two traits were strongly correlated on both chow $(r=0.43)$ and high fat $(r=0.63)$ diets, consistent with the possibility that apoAII protein levels influence HDL cholesterol levels. The fraction of HDL cholesterol levels that can be explained by apoAII levels, approximated by the square of the correlation coefficient, is $\sim 0.18$ for the chow diet and $\sim 0.40$ for the high fat diet.

Regulation of apoAII gene expression. Our results indicate

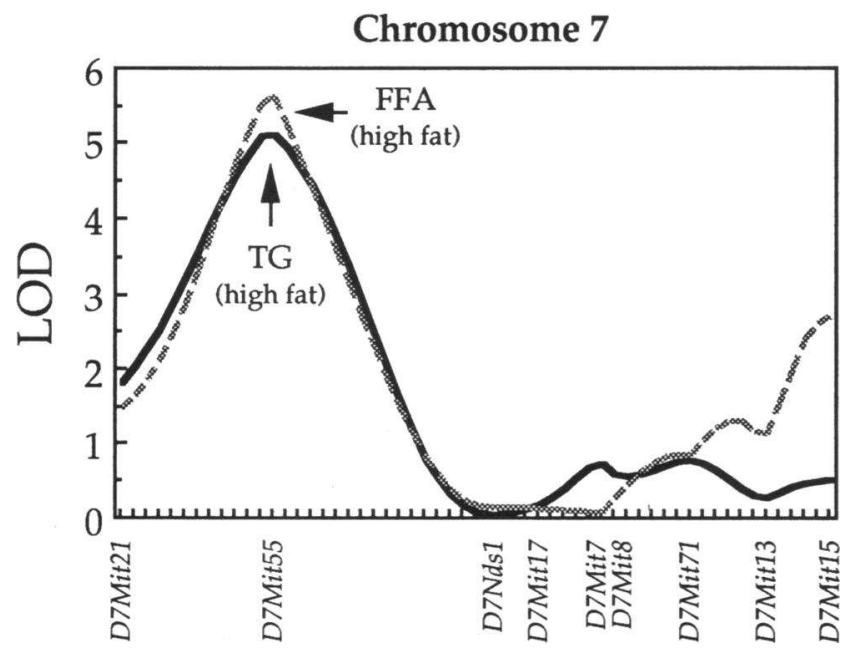

Figure 5. A locus on chromosome 7 which contributes to plasma TG and FFA levels on a high fat diet. The $x$-axis represents distances along chromosome 7 with D7Mit21 nearest to the centromere and D7Mit15 the most distal marker. Lod scores were calculated and plotted at 2-cM intervals, represented by ticks along the $x$-axis. For specific distances between markers refer to Fig. $2 \mathrm{~A}$. Lod scores were age adjusted (inclusive of both sexes ).
A

\section{Chromosome 1}
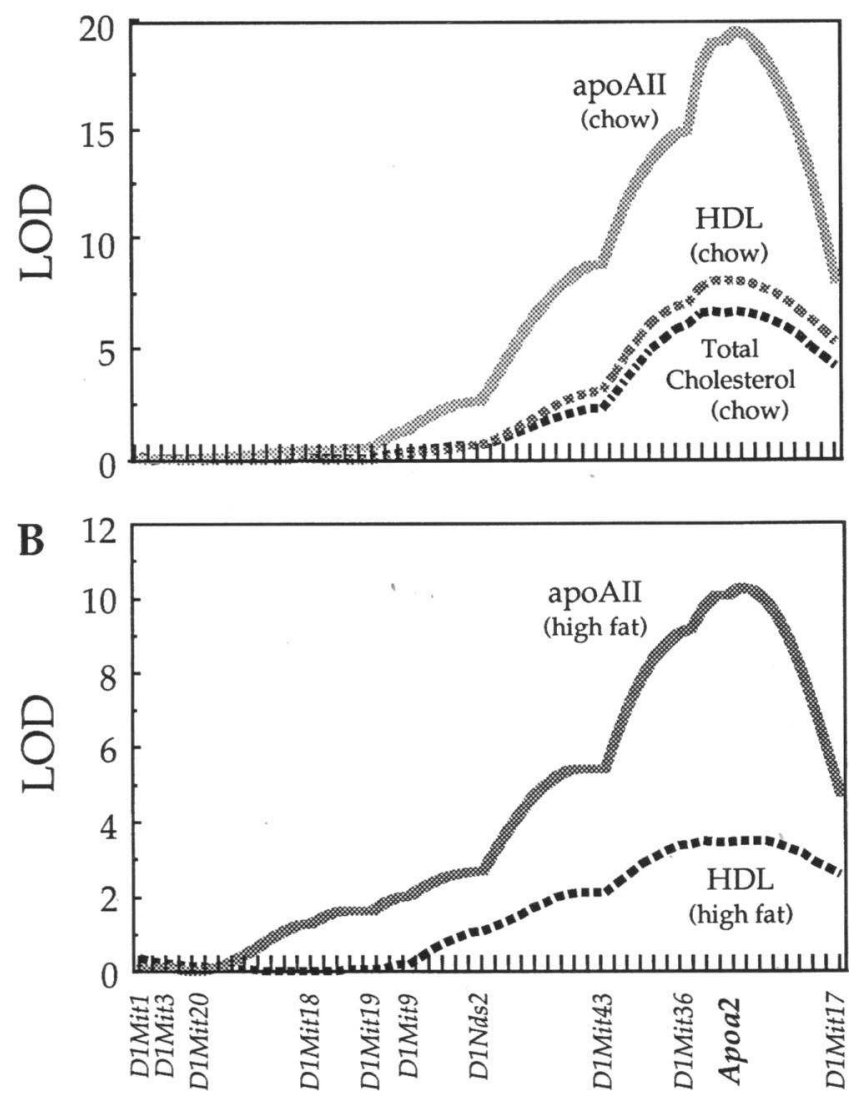

Figure 6. Lod score plots at the Apoa2 gene on chromosome 1. (A) Phenotypes measured on a chow diet, $(B)$ phenotypes measured on a high fat diet. The $x$-axis represents distances along chromosome 1 with DIMitl nearest to the centromere and D1Mit17 the most distal marker. Lod scores were calculated and plotted at 2-cM intervals. For specific distances between markers, refer to Fig. $3 \mathrm{~A}$. All values were adjusted to correct for differences due to sex and age.

that, on a chow diet, parental strains NZB and SM exhibit about a 10-fold difference in plasma apoAII expression (21 and 2 $\mathrm{mg} / \mathrm{dl}$, respectively) and that about one-third of this can be explained by the apoAII structural gene locus on chromosome 1 (Table III). As the liver is the only detectable site of apoAII gene expression (26), we compared apoAII mRNA levels from the livers of chow- and high fat-fed NZB and SM parental animals. Although there were no significant differences in apoAII mRNA levels between NZB and SM animals fed a high fat diet, there was an $\sim 1.5-2$-fold higher apoAII mRNA level in chow-fed SM animals relative to chow-fed NZB animals. This difference in apoAII mRNA levels in chow-fed animals is not a major determinant of apoAII levels in the two strains, as NZB has a 10-fold higher plasma apoAII level compared with SM. Thus, the cis component controlling apoAII expression (that component determined by the apoAII structural gene) must result from genetic alterations of the apoAII mRNA affecting the translation, secretion, and/or turnover of the apoAII protein. Therefore, we sequenced the cDNA of apoAII for each strain (Fig. 7). Two adjacent base pairs were found to differ between the two strains resulting in a proline in NZB and a glutamine in SM at position 5 of the mature protein. 
Table IV. Total and HDL Cholesterol Levels by Genotype at the D5Mit25 Marker

\begin{tabular}{|c|c|c|c|c|c|c|}
\hline \multirow[b]{2}{*}{ Trait } & \multicolumn{3}{|c|}{ Chow diet } & \multicolumn{3}{|c|}{ High fat diet } \\
\hline & $N N$ & NS & sS & $N N$ & NS & ss \\
\hline \multirow[t]{2}{*}{ Total cholesterol (mg/dl) } & $114 \pm 4$ & $103 \pm 2$ & $91 \pm 4$ & $230 \pm 13$ & $225 \pm 8$ & $211 \pm 15$ \\
\hline & $n=41$ & $n=96$ & $n=39$ & $n=40$ & $n=92$ & $n=37$ \\
\hline \multirow[t]{3}{*}{ HDL cholesterol (mg/dl) } & $102 \pm 3$ & $94 \pm 2$ & $84 \pm 3$ & $90 \pm 7$ & $84 \pm 5$ & $65 \pm 7$ \\
\hline & $n=41$ & $n=96$ & $n=39$ & $n=40$ & $n=92$ & $n=37$ \\
\hline & \multicolumn{3}{|c|}{ Chow diet } & \multicolumn{3}{|c|}{ High fat diet } \\
\hline Trait & $N N$ & $N S$ & sS & $N N$ & $N S$ & SS \\
\hline \multicolumn{7}{|l|}{ Total cholesterol } \\
\hline \multirow[t]{2}{*}{ Males } & $117 \pm 6$ & $110 \pm 4$ & $99 \pm 4$ & $263 \pm 16$ & $263 \pm 8$ & $244 \pm 20$ \\
\hline & $n=19$ & $n=52$ & $n=24$ & $n=18$ & $n=49$ & $n=22$ \\
\hline \multirow[t]{3}{*}{ Females } & $111 \pm 4$ & $94 \pm 2$ & $77 \pm 5$ & $204 \pm 18$ & $182 \pm 12$ & $164 \pm 16$ \\
\hline & $n=22$ & $n=44$ & $n=15$ & $n=22$ & $n=43$ & $n=15$ \\
\hline & $P<0.4313$ & $P<0.0004$ & $P<0.0034$ & $P<0.0199$ & $P<0.0001$ & $P<0.0097$ \\
\hline \multicolumn{7}{|l|}{ HDL } \\
\hline \multirow[t]{2}{*}{ Males } & $104 \pm 5$ & $101 \pm 3$ & $92 \pm 4$ & $121 \pm 8$ & $114 \pm 6$ & $84 \pm 8$ \\
\hline & $n=19$ & $n=52$ & $n=24$ & $n=18$ & $n=49$ & $n=22$ \\
\hline \multirow[t]{3}{*}{ Females } & $101 \pm 4$ & $85 \pm 2$ & $70 \pm 4$ & $64 \pm 6$ & $51 \pm 4$ & $36 \pm 5$ \\
\hline & $n=22$ & $n=44$ & $n=15$ & $n=22$ & $n=43$ & $n=15$ \\
\hline & $P<0.6858$ & $P<0.0003$ & $P<0.0017$ & $P<0.0001$ & $P<0.0001$ & $P<0.0001$ \\
\hline
\end{tabular}

Shown are the total cholesterol and HDL cholesterol levels by genotype at the D5Mit25 marker: homozygous for NZB allele (NN), heterozygous $(N S)$ and homozygous for SM allele (SS). Data are listed as mean value \pm SE. $P$ values listed are for the differences in male versus female values.

To test whether these mutations influence the rate of synthesis of apoAII by the liver, hepatocytes isolated from NZB and SM mice were pulse-labeled with $\left[{ }^{35} \mathrm{~S}\right]$ methionine. Aliquots of cells were removed at times $0,6,12$, and $18 \mathrm{~min}$ and were immediately lysed. Total TCA precipitable counts per milligram of protein and apoAII precipitable counts per milligram of protein were determined at each time point for three NZB females and two SM females. To ensure complete recovery of the apoAII protein, the cell lysates were reimmunoprecipitated. The relative rate of apoAII synthesis was calculated as apoAII immunoprecipitable counts per milligram of protein/total TCA precipitable counts per milligram of protein. As both NZB and SM contain three methionine residues per molecule of mature apoAII, there was no need to adjust the calculations of the relative rates of synthesis. The results of these experiments are presented in Table VI. The relative rate of synthesis for the NZB mice ranged from $0.12 \%$ to $0.20 \%$, and the range for the SM mice was $0.14-0.22 \%$. Although there was some variability

Table V. apoAII and HDL Cholesterol Levels by Genotype at the Apoa2 Gene

\begin{tabular}{|c|c|c|c|c|c|c|}
\hline \multirow[b]{2}{*}{ Trait } & \multicolumn{3}{|c|}{ Chow diet } & \multicolumn{3}{|c|}{ High fat diet } \\
\hline & $N N$ & NS & SS & $N N$ & $N S$ & SS \\
\hline \multicolumn{7}{|c|}{ apoAII (mg/dl) } \\
\hline Both & $\begin{array}{c}11.2 \pm 0.7 \\
n=39\end{array}$ & $\begin{array}{l}8.4 \pm 0.4 \\
n=87\end{array}$ & $\begin{array}{c}4.8 \pm 0.4 \\
n=51\end{array}$ & $\begin{array}{l}8.3 \pm 0.6 \\
n=38\end{array}$ & $\begin{array}{l}6.6 \pm 0.3 \\
n=87\end{array}$ & $\begin{array}{l}4.5 \pm 0.5 \\
n=50\end{array}$ \\
\hline \multicolumn{7}{|c|}{ HDL (mg/dl) } \\
\hline Both & $\begin{array}{l}108 \pm 3 \\
n=39\end{array}$ & $\begin{array}{l}95 \pm 2 \\
n=87\end{array}$ & $\begin{array}{l}82 \pm 2 \\
n=51\end{array}$ & $\begin{array}{l}93 \pm 8 \\
n=38\end{array}$ & $\begin{array}{l}84 \pm 5 \\
n=85\end{array}$ & $\begin{array}{l}67 \pm 6 \\
n=49\end{array}$ \\
\hline Males & $\begin{array}{l}115 \pm 4 \\
n=20\end{array}$ & $\begin{array}{c}100 \pm 4 \\
n=48\end{array}$ & $\begin{array}{l}88 \pm 3 \\
n=28\end{array}$ & $\begin{array}{c}126 \pm 8 \\
n=19\end{array}$ & $\begin{array}{l}111 \pm 6 \\
n=45\end{array}$ & $\begin{array}{l}89 \pm 8 \\
n=26\end{array}$ \\
\hline Females & $\begin{array}{c}100 \pm 4 \\
n=19 \\
P=0.019\end{array}$ & $\begin{array}{c}88 \pm 3 \\
n=41 \\
P=0.015\end{array}$ & $\begin{array}{c}75 \pm 3 \\
n=23 \\
P=0.006\end{array}$ & $\begin{array}{c}60 \pm 7 \\
n=19 \\
P<0.0001\end{array}$ & $\begin{array}{c}54 \pm 5 \\
n=40 \\
P<0.0001\end{array}$ & $\begin{array}{c}43 \pm 5 \\
n=23 \\
P<0.0001\end{array}$ \\
\hline
\end{tabular}

Shown are the apoAII protein and HDL cholesterol levels by genotype at the Apoa2 gene: homozygous for NZB allele (NN), heterozygous (NS) and homozygous for the SM allele (SS). Data are listed as mean value \pm SE. Comparison of values between genotypes for the males and females combined (Both) differed significantly $(P=0.0001)$ in all cases except for HDL (high fat) where there was no significant difference between NN and NS values. The $P$ values shown are for the comparison of HDL values between genotypes of the males and females. 
Table VI. Relative Rates of apoAII Protein Synthesis in $N Z B$ and $S M$

\begin{tabular}{cc}
\hline Strain and mouse No. & Average relative rate of synthesis \\
\hline & $\% \pm S D$ \\
NZB No. 1 & $0.12 \pm 0.04$ \\
NZB No. 2 & $0.16 \pm 0.05$ \\
NZB No. 3 & $0.20 \pm 0.02$ \\
SM No. 1 & $0.22+0.03$ \\
SM No. 2 & $0.14 \pm 0.01$ \\
\hline
\end{tabular}

The relative rate of synthesis is the incorporation of radioactivity into apoAII divided by total incorporation.

in the relative rates of apoAII synthesis among the individual animals, there was no significant difference in the relative rates between the NZB and SM animals. These small differences do not account for the 10-fold difference in apoAII protein levels between the two strains, suggesting that genetic regulation of apoAII levels occurs at the level of catabolism rather than synthesis.

\section{Discussion}

Animal models provide a general means for the identification of genetic factors contributing to complex, multifactorial traits $(11,13)$. Thus, the genotyping and phenotyping of progeny from genetic crosses between inbred strains differing for a complex trait of interest allows identification of the chromosomal regions contributing to that trait. We have applied this method to examine genetic factors contributing to large variations in lipoprotein metabolism between strains NZB and SM. 21 suggestive or significant loci were identified that contribute to plasma lipid, lipoprotein, or apolipoprotein levels on a chow or high fat diet. Whereas some of these loci corresponded to the positions of known candidate genes, most did not correspond to any previously mapped genes with obvious relevance to lipoprotein metabolism. Since most of the genes for known apolipoproteins, lipoprotein receptors, and enzymes mediating lipoprotein metabolism have been mapped in the mouse (35), this finding suggests the existence of novel genes that make important contributions to lipoprotein metabolism. Several of the loci identified were specific for either the chow or high fat diet, thus identifying elements which contribute to genetic-dietary interactions. Of the loci which corresponded to known candidate genes, we examined one in detail, that being the locus found at the Apoa 2 gene on chromosome 1 . The results provide strong confirmatory evidence that variations in the expression of apoAII contribute importantly to plasma levels of HDL cholesterol on both chow and high fat diets. They also provide a striking example of posttranscriptional regulation of protein expression.

Linkage analysis. A major issue with modern linkage and especially QTL mapping is the problem of the level of significance required to establish a statistically valid result. Simulation studies have provided guidelines for lod thresholds as a function of the genome size and the density of markers scored $(11,14)$. For the density of markers scored in our cross in the mouse (with a total genome size of $\sim 1,500 \mathrm{cM}$ ) such estimates sug-

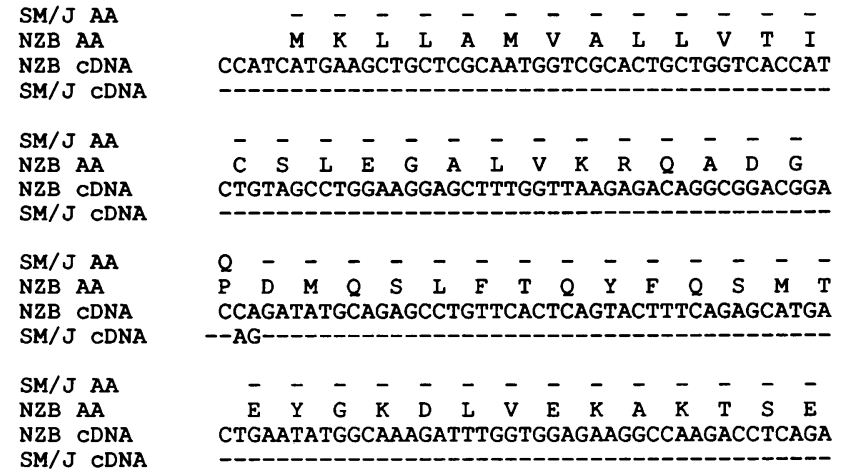

$\mathrm{M} / \mathrm{J}$ CDNA

\section{SM/J AA}

NZB AA

NZB CDNA

SM/J CDNA

$\begin{array}{llllllllllllll}\bar{I} & \bar{Q} & \bar{S} & \bar{Q} & \bar{V} & \bar{K} & \bar{A} & \bar{Y} & \bar{F} & \bar{E} & \bar{K} & \bar{T} & \bar{H} & \bar{E}\end{array}$ GATTCAGAGCCAGGTCAAGGCATACTTTGAGAAGACACACGAG

$S M / J$ AA

NZB AA

NZB CDNA

SM/J CDNA

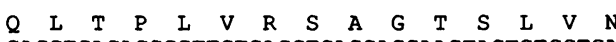
CAGCTGACACCCCTTGTCAGGTCAGCAGGACTAGTCTGGTGA

$S M / J$ AA

NZB AA

NZB CDNA

SM/J CDNA

$\begin{array}{llllllllllllll}\bar{F} & \bar{F} & \bar{S} & \bar{S} & \bar{L} & \bar{M} & \bar{N} & \bar{L} & \bar{E} & \bar{E} & \bar{K} & \bar{P} & \bar{A} & \bar{P}\end{array}$ ACTTCTTCAGCAGTTTAATGAACCTCGAGGAGAAACCGGCTCC

$S M / J A A$

NZB CDNA

NZB J CDNA

$\bar{A} \bar{K}$ *

TGCGGCTAAGTGAGATGTGCCAGGCCCAGTCTTCCCACCCCAGC

NZB CDNA

SM/JCDNA

TGCTCCACTGGCCACCGCTAGAGCCCCTCTCCCTGCCTTCTGCC

NZB CDNA TTTTTCGC

Figure 7. apoAII cDNA and protein sequences for NZB/BINJ and SM/ $\mathrm{J}$ mice. The respective cDNA and amino acid $(A A)$ sequences of the apoAII coding regions for both strains are shown. * indicates the stop codon. - indicates identical sequence, with differences indicated by the appropriate letter designation.

gest that a lod score of $\sim 3$ would ensure that the chance of observing a false positive is $<5 \%$ (Fig. 4 of reference 11 ). However, there are now a number of examples where reported significant linkages have failed the test of replication (14). Moreover, because multiple traits were typed (a total of 8 ) and because data were analyzed separately in males and females and using chow and high fat diets, the thresholds must be increased to take into account these additional comparisons ( 8 traits $\times 2$ sexes $\times 2$ diets $=32$ comparisons). If the traits scored were independent, the threshold level adjustment would be straightforward, but, clearly, many of the traits are highly correlated (Table II), indicating that a much smaller adjustment would be appropriate. The precise amount of adjustment required, however, is unclear. Although adjustments for multiple trait comparisons have usually been ignored in studies of complex traits in both animal models and humans, simultaneous analysis of multiple traits frequently will be both scientifically and economically advantageous.

Given the problem of multiple comparisons, we have adopted a conservative threshold of lod $=5.0$ for establishment of linkage. This threshold is in excess of that calculated by adjustment for multiple comparisons, particularly given the relatedness of the traits typed. We also report linkages in excess 
of 3.0, although these require confirmation and should be considered hypothesis generating.

Coincidence mapping. Our results provide very strong evidence that a locus on chromosome 7 contributes to both plasma triglyceride and free fatty acid levels. Thus, the lod scores observed (5.6 and 5.1, respectively) correspond to likelihood ratios (the ratio of the likelihood of linkage to the likelihood of no linkage) considerably $>100,000: 1$. A promising candidate gene that has been mapped to this region is that for hormonesensitive lipase, an enzyme that functions in the hydrolysis of triglycerides in certain tissues, releasing free fatty acids into the circulation (36). No known variations in hormone-sensitive lipase have been described previously. Other candidates residing at the chromosome 7 locus are members of the apoE-apoCIIapoCI gene cluster. Each of these apolipoproteins functions in the metabolism of triglyceride-rich lipoproteins, but there is no evidence that they would influence free fatty acid levels. The effect of the chromosome 7 locus on triglyceride levels may be secondary, since free fatty acids are thought to stimulate VLDL synthesis (37).

Our study revealed strong evidence for linkage of apoAII levels and HDL cholesterol levels with the apoAII structural gene on chromosome 1 . Several observations support the conclusion that variations of the apoAII gene influence plasma apoAII levels which in turn influence HDL cholesterol levels. First, the peak lod scores for both apoAII levels and HDL cholesterol levels were precisely coincident with the Apoa2 gene. The locus accounted for $\sim 42 \%$ of plasma apoAII variance and $18 \%$ of HDL cholesterol variance for chow-fed animals. Second, plasma apoAII levels were correlated with HDL cholesterol levels on both chow $(r h o=0.43)$ and high fat ( $r h o=0.63$ ) diets. Third, although mRNA levels for apoAII exhibited only small differences between chow-fed parental strains and no significant differences between high fat-fed parental strains, gene sequencing revealed two nucleotide substitutions in the coding regions of the apoAII transcript resulting in a single amino acid difference between the apoAII of NZB and SM. These findings were consistent with other recent studies. One study with recombinant inbred strains of mice suggested that apoAII expression could contribute to HDL cholesterol levels, but because of the small number of available recombinant inbred strains these results were not conclusive (23). Strong evidence that apoAII contributes to HDL cholesterol levels was obtained in studies with transgenic mice overexpressing mouse apoAII $(24,33)$. However, such transgenic studies were pharmacologic in the sense that the effects from the unusually high levels of apoAII (severalfold higher than observed in native mice) may have resulted from nonphysiologic mechanisms.

Novel genes contributing to lipoprotein metabolism. Most of the loci identified in this study did not coincide with the positions of known candidate genes. Evidence for the importance of several of these loci is very strong; for example, the chromosome 5 region that controls HDL cholesterol levels exhibits a likelihood ratio greater than one million to one. Such loci can now be isolated by specific breeding onto common genetic backgrounds as congenic strains, making possible fine structure mapping and positional cloning (35). It is possible that such novel genes also contribute to genetic variations in lipoprotein metabolism in humans. This can be tested by examining the segregation of genetic markers in the homologous regions of the human genome in families characterized for lipo- protein parameters. For example, the mouse chromosome 5 region determining HDL cholesterol is predicted to correspond on the basis of synteny to the distal region of human chromosome 7. The genetic basis for most of the variance found in plasma lipoproteins is presently unknown, despite extensive studies with candidate genes. These variations include clinically significant and common disorders such as familial combined hyperlipidemia and familial hypoalphalipoproteinemia. If such disorders result from alterations in currently unidentified genes, animal studies can provide a valuable means for their identification and characterization (38).

It is of interest that the loci for total cholesterol levels identified in this cross between NZB and SM were noncoincidental with two loci identified for total cholesterol on chromosomes 6 and 7 in a cross between Mus spretus and C57BL/6J (17). This difference in detectable loci between different sets of crosses may be reflective of differences in the strength of the contributing QTLs among the strains involved in a particular cross. Different genetic backgrounds can influence the strength of a QTL. For example, this modifying role of genetic background upon QTL strength has been observed in crosses involving the Multiple intestinal neoplasia (Min) mouse (39).

Genetic-dietary interactions and gender effects in lipoprotein metabolism. Genetically determined differences in the responsiveness to dietary cholesterol and fat occur in human populations but have proven difficult to examine in detail (40). Our results have revealed several genetic loci in mice whose effects are specific for a particular diet. The isolation of these loci by selective breeding should facilitate biochemical and physiologic studies to examine the specific properties of the underlying genes within these chromosomal regions.

Similarly, several loci were also gender specific. This is not unexpected since both mice and humans exhibit substantial gender-dependent differences in lipoprotein metabolism and susceptibility to atherosclerosis. For example, women tend to have higher HDL cholesterol levels and lower LDL cholesterol levels than men, and before menopause women are less susceptible to atherosclerosis than men. On the other hand, in certain strains of mice it is the females that exhibit lower HDL cholesterol levels than the males, particularly when maintained on a high fat diet, and females tend to be more susceptible to the development of aortic fatty streak lesions than males $(22,32$, 33). Strain C57BL/6J mice have been studied in the greatest detail. On a chow diet, both male and female C57BL/6J mice have comparable HDL cholesterol levels, but when maintained on high fat, atherogenic diets, similar to that used in this study, the HDL cholesterol levels of females, but not males, decrease about twofold. Genetic studies with recombinant inbred strains derived from C57BL/6J and various other strains in which female mice maintain high HDL cholesterol levels on a high fat diet have suggested the existence of two major genes, designated Ath-1 and Ath-2, which control the response of HDL cholesterol levels to a high fat diet as well as susceptibility to atherosclerosis $(22,41)$. Unfortunately, the relatively small number of different recombinant inbred strains currently available has allowed only tentative mapping of these genes. The gender-specific loci identified in this study could potentially contribute to such sex-specific, but genetically determined, changes in lipoprotein levels. In regard to Ath-1 and Ath-2, the chromosome 5 locus for HDL cholesterol is of particular interest since its effects are largely restricted to females.

Posttranscriptional regulation of apoAII expression. $42 \%$ 
of the plasma apoAII variance in F2 animals on a chow diet and $23 \%$ of the apoAII variance in F2 animals on a high fat diet could be attributed to the apoAII locus. The lack of significant mRNA differences between the high fat-fed parental NZB and SM strains indicates that the effect of the apoAII locus on apoAII levels is predominantly posttranscriptional. Moreover, the failure to observe any significant differences between the relative rates of apoAII synthesis in chow-fed animals implies a posttranslational mechanism affecting the apoAII clearance rate between the two strains.

The lack of any major effect on the rate of apoAII synthesis resulting from the proline to glutamine substitution at position 5 of the mature apoAII protein in SM suggests a possible mechanism contributing to the differences in apoAII levels between the two strains. It has been shown that the presence of a glutamine residue at position 5 of apoAII results in apoAII amyloid deposition in the senescence-accelerated prone mouse (SAMP) strains before $1 \mathrm{yr}$ of age $(42,43)$. Moreover, it has been shown that there is an increase in the rate of apoAII clearance from plasma before amyloid deposition in the SAM-P strains carrying the glutamine residue (44). The SM strain has been reported to develop amyloidosis at $1 \mathrm{yr}$ of age or older (45), but it is unclear what type of amyloid is deposited. It is possible that a structural difference in apoAII from the SM strain caused by the presence of the glutamine residue at position 5 predisposes the apoAII protein to an accelerated clearance with subsequent amyloid deposition. The altered apoAII metabolism may in turn alter HDL metabolism, resulting in the lower HDL levels observed in the SM mice. Other genetic and environmental factors (such as the high fat diet) affecting lipid metabolism may further influence apoAII clearance as well.

\section{Acknowledgments}

We thank Yu-Rong Xia for technical assistance in typing the F2 progeny mice by Southern analysis of the Apoa 2 gene. We are grateful to Dr. Jerome Rotter and Dr. Hongu Zhao for discussions.

This work was supported in part by National Institutes of Health grants HL-42488 (A. J. Lusis) and HL-28481 (M. H. Doolittle). Ari Weinreb was supported by Medical Genetics-UCLA Intercampus Program Training Grant GM08243.

\section{References}

1. Brown, M. S., and J. L. Goldstein. 1986. A receptor mediated pathway for cholesterol homeostasis. Science (Wash. DC). 232:34-47.

2. Young, S. G. 1990. Recent progress in understanding apolipoprotein B. Circulation. 82:1574-1594.

3. Doolittle, M. H., A. Durstenfeld, A. S. Garfinkel, and M. C. Schotz. 1992. Triglyceride lipases, hypertriglyceridemia and atherosclerosis. In Molecular Genetics of Coronary Artery Disease: Candidate Genes and Processes in Atherosclerosis. A. J. Lusis, J. I. Rotter, and R. S. Sparkes, editors. Karger, Basel. 172188.

4. Tall, A. R. 1990. Plasma high density lipoproteins. Metabolism and relationship to atherogenesis. J. Clin. Invest. 86:379-384

5. Karathanasis, S. K. 1992. Lipoprotein metabolism: high-density lipoproteins. In Molecular Genetics of Coronary Artery Disease: Candidate Genes and Processes in Atherosclerosis. A. J. Lusis, J. I. Rotter, and R. S. Sparkes, editors. Karger, Basel. 140-171.

6. Schumaker, V., and A. Lembertas. 1992. Lipoprotein metabolism: chylomicrons, very-low density lipoproteins and low-density lipoproteins. In Molecular Genetics of Coronary Artery Disease: Candidate Genes and Processes in Atherosclerosis. A. J. Lusis, J. I. Rotter, and R. S. Sparkes, editors. Karger, Basel. 98139.

7. Lusis, A. J. 1988. Genetic factors affecting blood lipoproteins: the candidate gene approach. J. Lipid Res. 31:91-102.

8. Davignon J., R. E. Gregg, and C. F. Sing. 1988. Apolipoprotein E polymorphism and atherosclerosis. Arteriosclerosis. 8:1-21.
9. Breslow, J. L. 1989. Genetic basis of lipoprotein disorders. J. Clin. Invest. 84:373-380.

10. Mehrabian, M., and A. J. Lusis. 1992. Genetic markers for studies of atherosclerosis and related risk factors. In Molecular Genetics of Coronary Artery Disease: Candidate Genes and Processes in Atherosclerosis. A. J. Lusis, J. I. Rotter, and R. S. Sparkes, editors. Karger, Basel. 363-418.

11. Lander, E. S., and D. Botstein. 1989. Mapping Mendelian factors underlying quantitative traits using RFLP linkage maps. Genetics. 121:185-199.

12. Paterson, A. H., S. Damon, J. D. Hewitt, D. Zamir, H. D. Rabinowitch, S. E. Lincoln, E. S. Lander, and S. D. Tanksley. 1991. Mendelian factors underlying quantitative traits in tomato: comparison across species, generations, and environments. Genetics. 127:181-197.

13. Warden, C. H., A. Daluiski, and A. J. Lusis 1992. Identification of new genes contributing to atherosclerosis: the mapping of genes to complex disorders in animal models. In Molecular Genetics of Coronary Artery Disease: Candidate Genes and Processes in Atherosclerosis. A. J. Lusis, J. I. Rotter, and R. S. Sparkes, editors. Karger, Basel. 419-441.

14. Lander, E. S., and N. S. Schork. 1994. Genetic dissection of complex traits. Science (Wash. DC). 265:2037-2048.

15. Lusis, A. J., L. W. Castellani, and J. S. Fisler. 1992. Fitting pieces from studies of animal models into the puzzle of atherosclerosis Curr. Opin. Lipid. 3:143-150.

16. Todd, J. A., and S. C. Bain. 1992. A practical approach to identification of susceptibility genes for IDDM. Diabetes. 41:1029-1034.

17. Warden, C. H., J. S. Fisler, M. J. Pace, K. L. Svenson, and A. J. Lusis 1993. Coincidence of genetic loci for plasma cholesterol levels and obesity in a multifactorial mouse model. J. Clin. Invest. 92:773-779.

18. West, D. B., J. Groudy-Lefevre, B. York, and G. E. Truett. 1994. Dietary obesity linked to genetic loci on chromosome 9 and 15 in a polygenic mouse model. J. Clin. Invest. 94:1410-1416.

19. West, D. B., J. Waguespack, B. York, J. Goudey-Lefevre, and R. A. Price. 1994. Genetics of dietary obesity in AKR/J $\times$ SWR/J mice: segregation of the trait and identification of a linked locus on chromosome 4. Mammal. Gen. 5:546552.

20. Jacob, H. J., K. Lindpaintner, S. E. Lincoln, K. Kusumi, R. K. Bunker, Y. P. Mao, D. Ganten, V. J. Dzau, and E. S. Lander. 1991. Genetic mapping of a gene causing hypertension in the stroke-prone spontaneously hypertensive rat. Cell. 67:213-224.

21. Hilbert, P., K. Lindpainter, J. S. Beckman, T. Serikawa, F. Soubrier, C. Dubay, P. Cartwright, B. DeGouyon, C. Julier, S. Takahasi, et al. 1991. Chromosomal mapping of two genetic loci associated with blood pressure regulation in hereditary hypertensive rats. Nature (Lond.). 353:521-529.

22. Paigen, B., D. Mitchell, K. Reue, A. Morrow, A. J. Lusis, and R. C. LeBoeuf. 1987. Ath-1, a gene determining atherosclerosis susceptibility and high density lipoprotein levels in mice. Proc. Natl. Acad. Sci. USA. 84:3763-3767.

23. Mehrabian, M., J. H. Qiao, R. Hyman, D. Ruddle, C. Laughton, and A. J. Lusis. 1993. Influence of the apoAII gene locus on HDL levels and fatty streak development in mice. Arterioscler. Thromb. 13:1-10.

24. Hedrick, C. C., L. W. Castellani, C. H. Warden, D. L. Puppione, and A. J. Lusis. 1993. Influence of mouse apolipoproteinAII on plasma lipoproteins in transgenic mice. J. Biol. Chem. 268:20676-20682.

25. Dieckmann, C. L., and A. Tzagoloff. 1985. Assembly of the mitochondrial membrane system. J. Biol. Chem. 260:1513-1520.

26. Doolittle, M. H., R. C. LeBoeuf, C. H. Warden, L. M. Bee, and A. J. Lusis. 1990. A polymorphism affecting apolipoprotein AII translational efficiency determines high density lipoprotein size and composition. J. Biol. Chem. 265:16380-16388.

27. Love, J. M., A. M. Knight, M. A. McAleer, and J. A. Todd. 1990. Towards construction of a high-resolution map of the mouse genome using PCR-analyzed microsatellites. Nucleic Acids Res. 18:4123-4130.

28. Dietrich, W. F., H. Katz, S. E. Lincoln, H. S. Shin, J. Friedman, N. C. Dracopoli, and E. S. Lander. 1992. A Genetic map of the mouse suitable for typing intraspecific crosses. Genetics. 131:423-447.

29. Lander, E. S., P. Green, J. Abrahamson, A. Barlow, M. J. Daly, S. E. Lincoln, and L. Newberg. 1987. MAPMAKER: an interactive computer package for constructing primary genetic linkage maps of experimental and natural populations. Genomics. 1:174-181.

30. Chomczynski, P., and N. Sacchi. 1987. Single-step method of RNA isolation by acid guanidinium thiocyanate-phenol-chloroform extraction. Anal. Biochem. 162:156-159.

31. Kirchgessner, T. G., R. C. LeBoeuf, C. A. Langner, S. Zollman, C. H Chang, B. A. Taylor, M. C. Schotz, J. I. Gordon, and A. J. Lusis. 1989. Genetic and developmental regulation of the lipoprotein lipase gene: loci both distal and proximal to the lipoprotein lipase structural gene control enzyme expression. $J$. Biol. Chem. 264:1473-1482.

32. Paigen, B., A. Morrow, C. Brandon, D. Mitchell, and P. A. Holmes. 1985. Variation in susceptibility to atherosclerosis among inbred strains of mice. Atherosclerosis. 57:65-73.

33. Warden, C. H., C. C. Hedrick, J. H. Qiao, L. W. Castellani, and A. J. 
Lusis. 1993. Atherosclerosis in transgenic mice overexpressing apolipoprotein AII. Science (Wash. DC). 261:469-472.

34. Fisler, J. S., C. H. Warden, M. J. Pace, and A. J. Lusis. 1993. BSB: new mouse model of multigenic obesity. Obesity Res. 1:271-280.

35. Lusis, A. J. 1993. The mouse model for atherosclerosis. Trends Cardiovasc. Med. 3:135-143.

36. Warden, C. H., R. C. Davis, M. Y. Yoon, D. Y. Hui, K. L. Svenson, Y. R Xia, A. Diep, K. Y. He, and A. J. Lusis. 1993. Chromosomal localization of lipolytic enzymes in the mouse: pancreatic lipase, colipase, hormone-sensitive lipase, hepatic lipase, and carboxyl ester lipase. J. Lipid Res. 34:1451-1455.

37. Despres, J. P., S. Moorjani, P. J. Lupien, A. Tremblay, A. Nadeau, and C. Bouchard. 1990. Regional distribution of body fat plasma lipoproteins, and cardiovascular disease. Arteriosclerosis. 40:497-511.

38. Copeland, N. G., N. A. Jenkins, D. J. Gilbert, J. T. Eppig, L. J. Maltais, J. C. Miller, W. F. Dietrich, A. Wenver, S. E. Lincoln, R. G. Steen, et al. 1993. A genetic linkage map of the mouse: current applications and future prospects. Science (Wash. DC). 262:57-66.

39. Dietrich, W. F., E. S. Lander, J. S. Smith, A. R. Moser, K. A. Gould, C. Luongo, N. Borenstein, and W. Dove. 1993. Genetic identification of Mom-1, a major modifier locus affecting Min-induced intestinal neoplasia in the mouse. Cell. 75:631-639.
40. Dreon, D. M., and R. M. Krauss. 1992. Gene-diet interactions in lipoprotein metabolism. In Molecular Genetics of Coronary Artery Disease: Candidate Genes and Processes in Atherosclerosis. A. J. Lusis, J. I. Rotter, and R. S. Sparkes, editors. Karger, Basel. 325-349.

41. Paigen, B., M. N. Nesbitt, D. Mitchell, D. Albee, and R. C. LeBoeuf. 1989. Ath-2, a second gene determining atherosclerosis susceptibility and high density lipoprotein levels in mice. Genetics. 122:163-168.

42. Yonezu, T., S. Tsunasawa, K. Higuchi, K. Kogishi, H. Naiki, K. Hanada, F. Sakiyama, and T. Takeda. 1987. A molecular-pathologic approach to murine senile amyloidosis. Serum precursor-apolipoprotein A-II variant $\left(\mathrm{Pro}^{5}\right.$ to $\mathrm{Gln}^{5}$ ) presents only in the senile amyloidosis-prone SAM-P/1 and SAM-P/2 mice. Lab. Invest. 57:65-70.

43. Naiki, H., K. Higuchi, A. Shimada, T. Takeda, and K. Nakakuki. 1993. Genetic analysis of murine senile amyloidosis. Lab. Invest. 68:332-337.

44. Naiki, H., K. Higuchi, T. Yonezu, M. Hosokawa, and T. Takeda. 1988. Metabolism of senile amyloid precursor and amyloidogenesis: age-related acceleration of apolipoprotein A-II clearance in the senescence accelerated mouse. Am. J. Pathol. 130:579-587.

45. Staats, J. 1985. Standardized nomenclature for inbred strains of mice: eighth listing. Cancer Res. 45:945-977. 